\title{
Dialética entre liberalismo, paternalismo de Estado e biopolítica. Análise conceitual, implicações bioéticas e democráticas
}

Fermin Roland Schramm

\section{Resumo}

Na cultura política do mundo ocidental costuma-se opor liberalismo e paternalismo, partindo do pressuposto de que o primeiro termo indica uma defesa do valor da liberdade individual, constitutiva da cultura dos direitos humanos, ao passo que o segundo negaria este valor. Este trabalho defende a tese de que tais termos, em seu conjunto, possuem relação de tipo dialético, pois o primeiro ocuparia o lugar de tese e o segundo de antítese, cuja síntese seria representada pelo momento da biopolítica, a qual constituiria, por sua vez, uma nova tese, iniciando novo processo dialético em que o lugar da antítese seria representado pela bioética, sendo que ambas confluiriam para uma nova síntese, representada pelo empoderamento dos cidadãos, constitutivo das sociedades democráticas, ou que se pretendem tais.

Palavras-chave: Bioética. Biopolítica. Democracia. Empoderamento. Liberdade. Paternalismo.

\section{Resumen}

Dialéctica entre liberalismo, paternalismo de Estado y biopolítica. Análisis conceptual, implicaciones bioéticas y democráticas

En la cultura política del mundo occidental es costumbre oponer liberalismo y paternalismo, suponiendo que el primer término indica una defensa del valor de la libertad individual, constitutiva de la cultura de los derechos humanos, mientras que el segundo podría negar este valor. En este trabajo se defiende la tesis de que tales términos, en su conjunto, tienen un tipo de relación dialéctica, ya que el primero tendría a ocupar el lugar de una tesis y el segundo aquel de una antítesis, siendo la síntesis representada por la biopolítica, que constituiría, a su vez, una nueva tesis, empezando un nuevo proceso dialéctico, dónde el lugar de la antítesis sería representado por la bioética, los cuales confluirían para una nueva síntesis, representada por el empoderamiento de los ciudadanos, y que es un elemento constitutivo de las sociedades democráticas, o que se pretenden como tales.

Palabras-clave: Bioética. Biopolítica. Democracia. Empoderamiento. Libertad. Paternalismo.

\begin{abstract}
Dialectics between liberalism, State paternalism, and biopolitics. The conceptual analysis and the democratic and bioethical implications

The political culture of the Western world often opposes liberalism and paternalism, assuming that the first term indicates a defense of the value of individual freedom, constitutive of the human rights culture, while the second would deny this value. This paper defends the thesis that such terms, as a whole, have a dialectical relationship, because the first would take the place of a thesis and the second of an antithesis, which synthesis would be represented by the moment of biopolitics, which would in turn, constitute a new thesis, in a new dialectical process in which the place of the antithesis would be represented by bioethics, both of which would converge in a new synthesis, represented by the empowering of people, and that is constitutive of democratic societies, or that claim themselves as such.

Key words: Bioethics. Biopolitics. Democracy. Empowerment. Freedom. Paternalism.
\end{abstract}

Pós-doutor rolandschram@yahoo.com.br - Escola Nacional de Saúde Pública/Fundação Oswaldo Cruz (Ensp/Fiocruz), Rio de Janeiro/ RJ, Brasil.

\section{Correspondência}

Av. Augusto Severo, 132, apt ${ }^{\circ}$ 1.201, Glória CEP 20021-040. Rio de Janeiro/RJ, Brasil.

Declara não haver conflito de interesse. 
De acordo com a história política e social das democracias do mundo ocidental, inclusive da América Latina, os termos (a) "liberalismo" e (b) "paternalismo" remetem a ideias, crenças, ideologias, atitudes e formas de governar diferentes, que são vistas, quase sempre, como contraditórias ou antinômicas (do grego anti "contra" e nomos "lei"). O primeiro termo defenderia o valor da liberdade individual e o segundo o negaria, sendo, por isso, identificado, muitas vezes, com o termo "conservador", por oposição ao "progressista" liberal.

A tese aqui defendida é que (a) liberalismo e (b) paternalismo possuem uma relação de tipo dialético, o primeiro ocupando o lugar de tese e o segundo o da antítese, sendo a síntese representada pela (c) biopolítica. A biopolítica constituiria, então, uma nova tese, que faz parte de novo processo dialético no qual o lugar da antítese seria representado pela (d) bioética, sendo que ambas confluiriam para uma nova síntese, representada pelo (e) empoderamento (ou libertação) dos cidadãos.

A seguir apresentaremos, inicialmente, esta aparente antinomia, analisando conceitualmente cada termo separadamente e, em seguida, relacionando-os dialeticamente entre si.

\section{Liberalismo e paternalismo: análise conceitual}

\section{(a) Liberalismo}

O termo "liberalismo" é de fato polissêmico, mas designa, em praticamente todos os seus usos, a centralidade outorgada, em política como em moral, ao indivíduo, aos seus direitos, às suas liberdades ${ }^{1}$. O termo pode indicar: 1) uma atitude frente aos problemas políticos, que visa limitar o poder do Estado para proteger a liberdade dos indivíduos; 2) uma doutrina econômica favorável ao mercado; 3) uma filosofia política que considera os direitos dos indivíduos o fundamento do laço político ou do 'contrato social'; podendo, inclusive, 4) se adaptar a escolhas políticas muito diversas, como aquelas dos democratas norte-americanos, considerados de "esquerda", ou as dos liberais franceses, identificados com a "direita" 2 .

Apesar de sua polissemia, os vários usos do termo "liberalismo" parecem compartilhar um denominador comum, constituído pelo projeto de limitar os poderes do Estado, e isso em nome da assim chamada cultura dos direitos humanos, entendidos essencialmente como propriedade inerente ao homem considerado como indivíduo, não como membro de uma associação, ou seja, como direitos sub- jetivos. Segundo esta proposição, a "vontade geral", supostamente representada pelo Estado soberano - que, ao se autolimitar, concede tais direitos aos cidadãos -, não se confunde nunca com a universalidade dos indivíduos que compõem a comunidade política, havendo, portanto, disjunção irredutivel entre a liberdade e o poder, o que implicaria em impor limites à atuação do Estado, colocando os 'direitos' acima da vontade geral ${ }^{3}$.

Concretamente, "liberalismo" remete ao tipo de sociedades identificadas como democracias liberais (...) onde os direitos humanos são reconhecidose, até onde for possível, respeitados, e, de qualquer maneira, sempre relembrados e defendidos, sendo pouco a pouco estendidos a tudo aquilo que se chama (...) as minorias ${ }^{4}$. Em outros termos, o sentido compartilhado pelas várias formas de liberalismo remete à centralidade atribuída ao indivíduo, ou seja, aos "direitos" e às "liberdades" de cada um, considerados constitutivos da cidadania e, portanto, da própria democracia. Entretanto, de acordo com a assim chamada "condição pós-moderna", caracterizada pela crise dos "grandes contos" ou "fim dos metarrelatos", e sua substituição progressiva pela legitimação pela performatividade e, em particular, pela substituição do princípio de uma metalinguagem universal por aquele de uma pluralidade de sistemas formais $e$ axiomáticos capazes de argumentar enunciados denotativos, tais sistemas [são] descritos em uma metalinguagem universal, mas não consistente ${ }^{5}$.

Neste contexto, parece que atualmente todo ator político prefira definir-se como "liberal" para não ser associado aos metarrelatos ideológicos centrados sobre entidades coletivas (ou supostamente tais) como a "nação", a "raça", a "classe", que resultaram em universos políticos e sociais autoritários e "concentracionários" (como o nazismo e o stalinismo). Ou seja, ser "liberal", hoje, parece implicar uma postura política que possui, sobretudo, uma dimensão 'negativa', de antitotalitarismo: em uma época, como a nossa, de crise dos 'grandes relatos', não tem quase nenhum ator político que não se defina liberal, tal é o temor de ser associado àquelas ideologias que, pondo o acento não sobre o indivíduo, mas sobre identidades coletivas (...) têm criado os universos concentracionários ${ }^{6}$.

\section{(b) Paternalismo}

O termo "paternalismo" remete à atitude de tratar outrem em conformidade com o que se pensa ser o seu bem, subordinando a esse bem as preferências eventuais, expressas ou não, dessa pessoa ${ }^{7}$. Em termos políticos, "paternalismo" é entendido como 
"paternalismo de Estado" e serve para indicar o tipo de governo em que os súditos se encontram frente a governantes na condição de filhos menores frente ao pater familias ${ }^{8}$. Mas o conceito "paternalismo de Estado" está inevitavelmente vinculado ao conceito "poder", podendo ser entendido como instância desvinculada da vontade dos súditos, não diversamente de quanto o poder do pai de família não depende da vontade dos filhos, pois o "paternalismo" visaria o bem dos cidadãos, mas sem ter em devida conta a sua participação, e mantendo uma fração [de] cidadãos na condição de menores políticos ${ }^{9}$.

É importante ressaltar, entretanto, que paternalismo de Estado não deve ser confundido com o estado de bem-estar social (welfare state), que - de acordo com o Manifesto em defesa da civilização não pode ser interpretado como uma mera reforma do capitalismo, mas sim como uma grande transformação econômica, social e política [e como] emergência de um Estado que institucionalizou a ética da solidariedade no qual o bem-estar de um só é possível quando os demais à sua volta encontram-se na mesma situação e a liberdade só é possível com igualdade e respeito ao outro, pois a autonomia do indivíduo significa a liberdade de se autorrealizar ${ }^{10}$.

Se compararmos os dois termos e seus respectivos significados, pode-se observar que "liberalismo" e "paternalismo" remetem a conteúdos e práticas que podem ser vistos como sendo prima facie "antinômicos", visto que o liberalismo atribui um valor particular (ou "central") ao indivíduo e o paternalismo não. Parece, portanto, que os dois termos denotam posições inconciliáveis, aparentemente "antinômicas", no que diz respeito à liberdade individual e a seu exercício.

Entretanto, toda antinomia que não seja de fato um paradoxo da razão pura (como é o caso da terceira antinomia da Crítica da razão pura de Kant, que aborda a antinomia entre a tese da necessidade de uma causa livre e a antítese de que toda causa é infinitamente condicionada, isto é, que possui a tese da necessidade da liberdade e a antítese de sua impossibilidade) que leve a uma conclusão logicamente impossivel, a partir de uma demonstração aparentemente correta, mas de fato paradoxal, pode ser inscrita em processo dinâmico, chamado de "dialético".

Isso é exatamente o caso de nossa abordagem e que será entendida como confronto entre ideias e opiniões contrastantes, para tentar mostrar como a dialética não indica somente um construto formal para "racionalmente" tentar dar conta das contradições representadas pelas antinomias - como pre- tendia Kant, que a considerava o momento em que o intelecto se torna razão capaz de dar conta das teses contraditórias representadas pelas antinomias que a razão encontra em seus percursos -, mas também um dispositivo que se refere à estrutura da realidade, como mostrará, por exemplo, Karl Marx ao descrever o capital como o lugar das contradições entre forças produtivas nas relações produtivas que se manifesta no conflito entre classes sociais (burguesia e proletariado).

Nesse processo - como já pretendia formalmente Hegel, que concebia a dialética como momento da crítica ao racionalismo político liberal porque este ocultaria a contradição interna entre indivíduo particular e lógicas políticas supostamente universais - o conflito entre tese e antítese pode ser superado por uma síntese que ao mesmo tempo em que preserva a conflituosidade tenta ultrapassá-la. Em suma, a antinomia entre tese e antítese pode resultar em uma síntese, entendida como processo que reconcilia uma tese e uma antitese ${ }^{11}$.

Em nosso caso, o lugar da tese é ocupado pelos conteúdos representados pelo termo liberalismo e neoliberalismo, e a antítese por aqueles indicados pelo termo paternalismo, ambos podendo dar origem a uma "síntese", como pode ser aquela indicada pelo terceiro termo do título: (c) "biopolítica", cujos conteúdos e práticas parecem anular a contradição entre "liberalismo" e "paternalismo" por serem, em princípio, capazes de incluir dialeticamente a ambos, visto que os dispositivos de controle da biopolítica podem, por exemplo, ser muito bem introjetados pelos próprios destinatários, pois estes podem considerá-los necessários para responder a suas necessidades e carências concretas.

Assim sendo, neste processo dialético em que existe um confronto praticamente infinito entre momentos instituídos (tese) e momentos instituintes (antítese), a síntese representada pela biopolítica (e seus dispositivos concretos de biopoder) pode também ser vista como o momento do começo de novo processo dialético, representado pela emergência de uma nova tese, que pode ser vista como o momento do exercício concreto dos mecanismos de poder (chamado biopoder) sobre a vida (humana ou não), ou seja, o momento em que a vida biológica entra (e interfere) nos fenômenos políticos e deve lidar com os conflitos envolvidos; cuja antítese pode ser constituída pela (d) "bioética", entendida como momento de questionamento e crítica, mas também de resistência à biopolítica e a seu reducionismo da política aos dados biológicos, e à inter-relação destes com a economia e a gestão, cuja síntese prática 
pode ser pensada como o momento teleológico do (e) "empoderamento" ou "libertação", entendidos como resultado existencial do exercício concreto da cidadania, representado pela democracia. $\mathrm{E}$ isso em um contexto necessariamente diferente daquele do "Estado de mal-estar social", em que sob o ideário liberal dos mercados, em nome da eficiência e da competição, a ética da solidariedade foi substituída pela ética da concorrência ou do desempenho ${ }^{10}$.

\section{A dialética entre biopolítica e bioética}

A biopolítica, ou - como preferem alguns - as biopolíticas, podem ser vistas, de acordo com a filologia do termo, como a reconfiguração da relação entre política e vida, referente ao fato desta ter se tornado objeto direto do exercício do poder, chamado, por isso, de "biopoder", e por concentrar-se sobre os corpos e sua produtividade, isto é, sobre a atividade governamental representada por lógicas econômicas e de gestão, ou seja, pelo encontro entre saberes e práticas de gestão da população produtiva, individuando na lógica e na práxis econômica a verdadeira governabilidade biopolítica moderna, utilitarista e orientada ao sucesso. Como sintetizou Michel Foucault: é preciso falar de 'bio-política' para designar aquilo que faz entrar a vida e os seus mecanismos no campo dos cálculos explícitos e faz do poder-saber um agente de transformação da vida humana ${ }^{12}$.

Mais especificamente, tratar-se-ia de uma "estatização do biológico", entendida no duplo sentido de um poder exercido, por um lado, sobre o indivíduo e seu corpo, e, por outro, sobre a coletividade, vista como "população", inclusive como "espécie", implicando, portanto, em "biopoder", cuja função seria a de gerir, controlar e disciplinar os corpos, a vida e a morte tanto dos indivíduos como das populações e até da espécie homo sapiens. Nas palavras do autor: Parece-me que um dos fenômenos fundamentais do século XIX tem sido [que] o poder tenha tomado a seu cargo a vida, numa perspectiva que podíamos chamar de assistencial. Trata-se, por assim dizer, de uma tomada do poder sobre o homem como ser vivo, de uma espécie de estatização do biológico, ou pelo menos de uma tendência em direção àquilo a que se poderia chamar a estatização do biológico (...) algo que não é mais uma anátomo-política do corpo humano, mas que chamaria uma 'biopolítica' da espécie humana ${ }^{13}$.

Neste sentido, pode-se defender o argumento de que a biopolítica representa o momento de superação da tradicional dicotomia Estado/sociedade, em prol de uma economia política da vida em geral ${ }^{14}$, e que, aqui, pode ser vista como a "síntese" entre conteúdos do "liberalismo" e conteúdos do "paternalismo" porque possui dimensão não desprezível do exercício do poder e porque é vista como conjunto de resistências e [de] experiências de subjetivação livre ou como a dimensão onde a vida se afirma como contrapoder que cria subjetividade baseada na potência produtiva ${ }^{15}$.

Em outros termos - como deixou claro o próprio Foucault -, existe vínculo profundo entre liberalismo e biopolítica, visto que a análise da biopolítica só pode ser feita quando compreendermos que o regime geral dessa razão governamental [que] podemos chamar de questão da verdade, em primeiro lugar da verdade econômica [na] razão governamental, e, consequentemente, se compreendermos o que está em jogo neste regime que é o liberalismo, que se opõe à razão de Estado - ou que [a] modifica fundamentalmente sem questionar seus fundamentos - [ou seja] é somente quando entendermos o que é o liberalismo que poderemos entender o que é a biopolítica ${ }^{16}$. Mas a biopolítica pode ser caracterizada como síntese também por levar a uma rápida conversão das liberdades em necessidades e dos direitos em deveres, atribuindo ao indivíduo novas obrigações ético-políticas e jurídicas em relação consigo e aos outros [e com relação] às quais deverá sentir-se cada vez mais na obrigação de responder (...) confiando no novo saber-poder biopolítico ${ }^{17}$.

De fato, a síntese da biopolítica pode referir-se e reagrupar fenômenos muito diferentes, como guerras para resolver problemas, formas de terrorismo resultantes da impossibilidade do diálogo, situações de estado de exceção e de enfraquecimento das garantias jurídicas em nome da segurança, ou, então, casos privados como aqueles de eutanásia difundidos pela mídia e o cinema que, assim, os tornam públicos ${ }^{18}$. Desta forma, fenômenos políticos muito diferentes podem ser subsumidos a um único conceito aparentemente referente à vida biológica, tradicionalmente entendida como pertencente ao campo da biologia e das ciências da vida em geral, mas que - como veremos mais adiante - pode ser vista, no caso dos seres humanos e seres sencientes em geral, como uma biologia extensa que inclui tanto as ciências da vida como as ciências humanas (corpos e almas, se quisermos), inscrevendo, desta maneira, a biopolítica em uma espécie de gestão da vida biológica, graças a um programa de proteção e de incremento que implica uma produção do humano e uma domesticação do ser (...) selecionando e rejeitando no inumano, e no subumano, aquelas vidas patógenas que a ameaçam ou que, simplesmente, são inadequadas ${ }^{19}$.

Mas, o fato de considerar o termo "biopolítica" como uma possível síntese dos conteúdos de "libera- 
lismo" e da sua vertente "neoliberal", por um lado, e "paternalismo", por outro, não exclui a possibilidade de tornar tal "síntese" o começo de novo processo dialético, no qual ao momento da tese, representada pela(s) biopolítica(s), podemos contrapor uma antítese, representada pelo saber-fazer da bioética, entendida como ferramenta crítica e normativa para a análise e a avaliação da moralidade da práxis humana no campo da biomedicina e da saúde, tendo como objetivo orientar as escolhas biopolíticas.

Em particular, nesta possível dialética biopolítica-bioética, a antítese, representada pela bioética, pode ser vista como sendo forma de resistência à biopolítica e ao biopoder; ou seja, uma alternativa à biopolítica [que seja capaz de] mediar as questões normativas envolvidas pela biopolítica e o biopoder, e isso como momento de exercício da potência frente ao biopoder, isto é, como empowerment dos cidadãos ${ }^{20}$.

\section{A bioética como desconstrução da biopolítica}

Do ponto de vista crítico, a bioética pode ser vista também como uma tentativa de desconstruir a conceituação de biopolítica, pois a indefinição conceitual desta permite associar o termo a um amplo espectro de significados, referentes a fenômenos tão diferentes como as biopolíticas públicas, de proteção $e$ welfare dos estados democráticos [e às] formas de bio-tanato-política [da] biocracia nazista. Por isso, tal multiplicidade remete à necessidade prática de desconstruir a biopolítica e, a partir desta desconstrução, tentar aplicar as ferramentas da bioética para detectar a moralidade (que inclui a imoralidade) da biopolítica e do biopoder, tentando reconstruir formas de resistência (...) ao serviço de possível controle democrático do controle, representado pelo poder exercido pelo biopoder e a biopolítica ${ }^{21}$.

De fato, segundo Roberto Esposito, o termo biopolítica seria marcado por evidente indefinição conceitual, visto que parece atravessado por uma incerteza [que] o impede de qualquer conotação estável [e que] parece fazer dele não só instrumento como também objeto de um áspero confronto, filosófico $e$ político, sobre a configuração e o destino de nosso tempo ${ }^{22}$. Contudo, esta "indefinição" parece ser a consequência de outra, referente ao próprio conceito "vida" denotado pelo termo biopolítica, isto é, resultado da própria indiscernibilidade das palavras gregas bíos e zoé, que remetem - ambas - ao latim vita, de onde deriva nosso termo "vida".

Essa inexatidão conceitual se reflete, como consequência, também na definição de biopolítica que remete sem mais para a dimensão da zoé, ou seja, da vida na sua expressão biológica mais simples ou, quando muito, à linha de conjunção ao longo da qualo bíos emerge sobre a zoé, naturalizando-se também ${ }^{23}$. Assim sendo, existiria, em substância, uma "dupla indiscernibilidade" no conceito de biopolítica, resultante do fato desta ser habitada por um termo que não Ihe convém - e que se arrisca mesmo a distorcer os seus traços mais marcantes, pois a definição de zoé é problemática por remeter a uma concepção de vida absolutamente natural (...) despojada de qualquer conotação formal, o que seria em essência inconcebível, ainda mais hoje, quando o corpo humano aparece mais desafiado, e até literalmente atravessado, pela técnica ${ }^{23}$.

Em seu trabalho de desconstrução, Esposito detecta aquilo que considera o impensado (ou mais bem o recalcado) da biopolítica, mas que, de fato, a nortearia ${ }^{24}$. Para o autor, tratar-se-ia do paradigma imunitário ${ }^{25}$, considerado como um mecanismo subjacente à própria biopolítica e que permitiria contornar as dificuldades resultantes de sua indefinição conceitual. A este respeito cumpre lembrar que a categoria imunidade, além de ser usada na saúde pública, é também utilizada pela teoria dos sistemas (Luhmann), na sociologia (Baudrillard) e na própria filosofia (Derrida). Nesta última área o conceito teria tendência a deslocar-se naquele de autoimunidade, apresentado como o último horizonte da política contemporânea e entendido como categoria histórica inextricavelmente conexa à modernidade e à sua preocupação com a autoconservação da vida e a proteção social contra a conflituosidade, isto é, com a autoimunização contra seus efeitos de dissolução ${ }^{25}$.

Ainda para Esposito, no paradigma imunitário (ou immunitas) bíos e nomos, vida e política, [são] os dois componentes de um único, incindível, conjunto que só adquire sentido a partir da relação entre eles; sendo que a imunidade não seria apenas a relação que liga a vida ao poder, mas o poder de conservação da vida, pois ao contrário de tudo o que pressupõe o conceito de biopolítica - entendido como resultado do encontro que em certo momento se dá entre os dois elementos componentes - deste ponto de vista não existe um poder externo à vida, assim como a vida não se dá nunca fora das relações de poder. Por esta razão, neste caso, a política só poderia ser vista como a possibilidade, ou o instrumento, de conservar a vida e a imunização como proteção negativa da vida ${ }^{26}$.

$\mathrm{Na}$ realidade, a ambiguidade do conceito de biopolítica parece permitir que o utilizemos para indicar fenômenos diferentes, como as biopolíticas públicas de assistência, proteção e welfare dos estados de- 
mocráticos, e as formas de biotanatopolítica, como foi o caso da "biopolítica" (ou biocracia) nazista, entre outras. As duas situações em que o mesmo termo "denso" - biopolítica - parece tornar indistinguíveis devem, no entanto, ser distintas, pois:

(a) no primeiro caso, a biopolítica se refere a políticas que visam garantir e reforçar a saúde da população, graças aos dispositivos de controle, gestão e intervenção sobre o corpo humano (do indivíduo) e sobre a espécie humana;

(b) no segundo caso, ao invés de uma interface entre bíos e polis, temos uma subsunção de polis a bíos (ou à própria zoé), isto é, a política subsumida à biologia e às suas leis.

Assim sendo, os conceitos de bíos e polis parecem ter dois tipos de relação lógica possível: 1) uma inter-relação sem nenhuma prioridade de um conceito sobre o outro (que os linguistas chamam de relação paratáctica); 2) uma relação de subsunção de um termo ao outro (que os linguistas chamam hipotáti$c a)$, que, por sua vez, também tem duas variantes:

(2a) a subsunção de bíos a polis, que corresponde ao tipo de relação que já existia, por exemplo, para Aristóteles;

(2b) a subsunção de polis a bíos, e, por sua vez, de bíos a zoé, como foi o caso inter alia da biocracia nazista.

Mas, apesar destas distinções lógicas, a anfibologia conceitual persiste. De fato, o termo biopolítica se encontra, atualmente, em vários contextos discursivos em que apareça a "dupla conceitual" representada pelas palavras bíos e política, ou seja, quando, com uma frequência cada vez maior, a política se ocupa de problemas da vida, quando na política se torna central o corpo daqueles que têm poder e daqueles que suportam o poder, mas mantendo uma particular mobilidade semântica, uma instabilidade que é a prova da vitalidade do termo e da exigência [de] encontrar um nome/conceito [capaz de] enfocar comportamentos e relações que o léxico tradicional não conseguia mais captar e capaz de orientar uma série de fenômenos novos (...) destacando a implicação vital que o antigo léxico [da política] ocultava ${ }^{27}$. Porém, se admitirmos a possibilidade de a biopolítica fazer parte de novo processo dialético, junto com a bioética, entendida como sua antítese, qual poderia ser, de fato, a relação entre biopolítica (tese) e bioética (antítese)?

Uma das maneiras de relacionar dialeticamente biopolítica e bioética consistiria em pensar, por exemplo, no uso problemático do conceito 'vida' em bioética e suas interfaces com a práxis biopolítica e os dispositivos de biopoder ${ }^{28}$. Em particular, considerando que a confusão pode surgir quando considerarmos que bioética, biopolítica e biopoder têm a referência comum ao conceito bíos, como pode ser o caso quando falamos em "ética da vida", "política $d a$ vida" e "poder da vida", mas entendermos, de fato, "ética sobre a vida", "política sobre a vida" e "poder sobre a vida". Em realidade, neste caso, a referência a bíos não permite dizer se é sempre o mesmo sentido que se está a utilizar, ou não.

Com efeito, na referência ao termo bíos, feita pela dupla biopoder/biopolítica, o primeiro termo se refere aos dispositivos de efetivo exercício do poder sobre a vida e o segundo, à política que visa implementar e administrar o biopoder, razão pela qual se poderia dizer que esta referência a bíos, feita no caso da biopolítica/biopoder, é diferente daquela feita pela bioética, pelo menos se a entendermos não tanto como ferramenta descritiva ou normativa da práxis humana que envolve a vida (como ela de fato também é), mas como forma prática de resistência à biopolítica e às formas de biopoder ou como momento de exercício da potência frente ao biopoder; isto é, como empowerment ('libertação') dos cidadãos ${ }^{29}$.

Entretanto, nesta dialética, a bioética (entendida como forma de resistência à biopolítica e ao biopoder) deve ser vista não tanto como substituta (ou representante) do controle social (que é de fato garantia da democracia) - pois isso poderia aproximá-la de alguma forma de paternalismo -, mas como ferramenta de resistência ao serviço deste possível controle democrático do controle (representado pelo poder exercido pelo biopoder e a biopolítica) e que é indicado, por exemplo, por outro termo denso: empowerment (empoderamento, libertação...).

Contudo, dizer isso é ainda insuficiente, visto que não existe consenso nem sobre as relações existentes entre biopolítica e biopoder. De fato, existe quem considere que a dupla biopoder - biopolítica deva ser vista como uma relação de oposição biopoder/biopolítica. Este é o caso, por exemplo, de Antonio Negri e Michael Hardt, que consideram o biopoder - representado pela potência da multidão - como oposto à biopolítica ou como uma sua forma de resistência ${ }^{30}$. Para Jacques Rancière, entretanto, essa interpretação de Hardt e Negri deveria ser evitada, pois acabaria por reafirmar um enraizamento vitalista da política ${ }^{31}$.

Uma maneira, aparentemente mais promissora, de enfrentar tais dificuldades seria trocar o agente da resistência, tanto à biopolítica como ao biopoder, identificando-o, por exemplo, com a bioética, enten- 
dida como dispositivo capaz de dar um conteúdo moral à biopolítica, ou seja, capaz de submeter a política às normas morais capazes de legitimá-la ou de deslegitimá-la, retomando, portanto, os conteúdos como aqueles defendidos, por exemplo, pelo Movimento pela Ética na Política, de 1992, no Brasil.

Entrementes, esta "pretensão" da bioética deveria saber responder "dialeticamente" à crítica vinda do próprio campo, pois existem autores que consideram que a bioética tenha se tornado, nos últimos tempos, uma disciplina em risco, devido a um excessivo academicismo, aparentemente focado em problemas pontuais e irrelevantes quando comparados com os grandes temas como iniquidade social, políticas públicas sanitárias, crise ecológica, que estariam de fato sendo assumidos ou anexados pela própria biopolítica, devendo-se, assim, impedir sua apropriação desde outros flancos, alheios à agenda específica e prístina do pensamento bioético ${ }^{32}$

Tais riscos, apontados pelo bioeticista Miguel Kottow, certamente existem. Entretanto, tal condição de "risco" da bioética pode ser vista também como estímulo para pensar melhor uma bioética "resistente" - que incluiria, por exemplo, uma "bioética de intervenção [entendida como] análise de macroproblemas e conflitos coletivos ${ }^{33}-$, mas sabendo que isso só é possível se houver a desconstrução teórica prévia das categorias de biopolítica e de biopoder, e uma oposição ética e política concreta a uma anexação não justificada da bioética à biopolítica.

Ademais, entre os especialistas em biopolítica existe também quem inverte a relação, aqui proposta, entre biopolítica e bioética, considerando o termo biopolítica como definível per differentiam com relação à bioética, visto que a análise biopolítica ilumina criticamente o exercício de poder presente naqueles dispositivos morais e jurídicos que legitimam e organizam a ação normativa sobre a vida ${ }^{34}$. O debate sobre a relação entre biopolítica e bioética permanece, portanto, em aberto.

\section{Considerações finais}

O que podemos provisoriamente concluir desta desconstrução da categoria ambígua e densa de biopolítica? Desta entrada em campo político da vida biológica? E desta possível forma de resistência representada pela bioética?

A resposta não é simples se considerarmos que a biopolítica "não parte de um pressuposto filosófico [mas] de eventos concretos" ${ }^{35}$ (como foi o caso paradigmático da biocracia nazista) e que esta entrada em cena da vida (na sua dupla dimensão de bíos e zoé) parece desafiar nossas categorias políticas, fundadas historicamente na separação zoé/bíos e na prioridade léxica do bíos sobre a zoé.

Mas, ainda de acordo com Esposito, esta seria justamente a força da perspectiva biopolítica, sua capacidade de ler este emaranhado e este conflito, este deslocamento e esta implicação ${ }^{36}$, devendo-se, no entanto, saber que a vida biológica dos indivíduos e da população [instalou-se faz tempo] no centro de todas as decisões políticas significativas, o que nos obrigaria a uma mudança de paradigma, pois o modelo da cura médica tem se tornado não só o objeto privilegiado, mas a própria forma da vida política, isto é, de uma política que só na vida encontra a única fonte de legitimação possível ${ }^{37}$.

Nestas condições, qual seria, então, o papel da bioética frente à biopolítica? Uma maneira de responder consistiria em dizer que a bioética representaria uma alternativa "libertadora" frente à biopolítica, pois em princípio poderia mediar as questões normativas envolvidas pelas relações que se estabelecem entre bíos e zoé, e entre estes e a polis.

Porém, surge outra pergunta: qual seria a legitimidade da bioética para fazer isso? Uma resposta possível - como vimos - é que tal legitimidade seria dada resistindo à redução biopolítica do político, e, conceitualmente, à subsunção do bíos à zoé. Ou, talvez, utilizando a ferramenta da profanação do assim chamado 'inevitável' natural estabelecido entre a biologia e a política pelo paradigma biopolítico, entendendo a profanação como um deslocamento, sem abolição daquilo que se pretende deslocar, dos dispositivos de poder, e restituindo ao uso comum os espaços que [o poder] tinha confiscado ${ }^{38}$. Estes parecem ser os conteúdos da dialética entre biopolítica e bioética, que tentamos delinear aqui, cuja possível síntese seria o empoderamento dos cidadãos num tipo de sociedade que podemos chamar, por isso, de democrática. 


\section{Referências}

1. Cofrancesco D. Liberalismo. In: Esposito R, Galli C, organizadores. Enciclopedia del pensiero político. Bari: Laterza; 2005. p. 464-7.

2. Raynaud P. Libéralisme. In: Mesure S, Savidan P, organizadores. Dictionnaire des sciences humaines. Paris: PUF; 2006. p. 690-2.

3. Raynaud P. Op. cit. p. 691.

4. Lyotard JF. Moralités postmodernes. Paris: Galilée; 1999. p. 108.

5. Lyotard JF. La condition postmoderne. Paris: Ed. de Minuit; 1979. p. 72.

6. Cofrancesco D. Op. cit. p. 464.

7. Nilstun T. Paternalismo. In: Hottois G, Missa JN, organizadores. Nova enciclopédia da bioética. Lisboa: Piaget; 2003. p. 518-20.

8. Ornaghi L. Paternalismo. Enciclopedia filosofica. Milano: Bompiani; 2006. v. 9. p. 8.385-7.

9. Berardi R. Paternalismo. Op. cit. 2006. v. 9. p. 8.386-7.

10. Abaixo-assinado Manifesto em Defesa da Civilização. Petição Pública Brasil. [Internet]. (acesso 19 fev. 2014). Disponível: http://www.peticaopublica.com.br/PeticaoVer.aspx?pi=P2012N30206

11. Blackburn S. Dicionário Oxford de filosofia. Rio de Janeiro: Zahar; 1997. p. 363.

12. Foucault M. Histoire de la sexualité: la volonté de savoir. Paris: Gallimard; 1976. v. 1. p. 188.

13. Foucault M. II faut défendre la sociéte. Paris: Gallimard; 1997. p. 213-6.

14. Revel J. Biopolitique. Dictionnaire Foucault. Paris: Ellipses; 2008. p. 26.

15. Marzocca O. Biopolitica. In: Vittorio P, Marzocca O, Romano O, Russo A, Simone A, organizadores. Lessico di biopolitica. Roma: Manifestolibri; 2006. p. 50-6.

16. Foucault M. Naissance de la biopolitique. Paris: Gallimard; 2004. p. 24.

17. Marzocca O. Op. cit. p. 53-6.

18. Bazzicalupo L. Biopolítica: una mappa concettuale. Roma: Carocci; 2010. p. 137.

19. Bazzicalupo L. Op. cit. p. 20.

20. Schramm FR. A bioética como forma de resistência à biopolítica e ao biopoder. Rev. bioét. [Internet]. 2010 (acesso 19 fev. 2014);18(3):519-35. Disponível: http://revistabioetica.cfm.org. br/index.php/revista_bioetica/article/view/583/588

21. Schramm FR. Op. cit. p. 528-9.

22. Esposito R. Bios: biopolítica e filosofia. Lisboa: Ed. 70; 2010. p. 30.

23. Esposito R. Op. cit. p. 31.

24. Campbell T. Politica, immunità, vita: il pensiero di Roberto Esposito nel dibattito filosofico contemporaneo. In: Esposito R. Termini della politica: comunità, immunità, biopolitica. Milano: Mimesis; 2008. p. 9-61.

25. Campbell T. Op. cit. p. 15-6.

26. Esposito R. Op. cit. 2010. p. 74.

27. Bazzicalupo L. Op. cit. p. 13.

28. Schramm FR. O uso problemático do conceito 'vida' em bioética e suas interfaces com a práxis biopolítica e os dispositivos de biopoder. Rev. bioét. (Impr.). 2009;17(3):377-89.

29. Schramm FR. Op. cit. 2009. p. 384.

30. Hardt M, Negri A. Impero. II nuovo ordine della globalizzazione. Milano: Rizzoli; 2002.

31. Ranciere J. Biopolitique ou politique? Multitudes. [Internet]. 2000 (acesso fev. 2014);1:88-93. Disponível: http://multitudes.samizdat.net/article.php3?id_article $=210$

32. Kottow M. Bioética: una disciplina en riesgo. Revista Redbioética. 2010;1(1):158-72.

33. Garrafa V, Porto D. Bioética de intervención. In: Tealdi JC, organizador. Diccionario latinoamericano de bioética. Bogotá: Unesco; 2008. p. 161-4.

34. Bazzicalupo L. Op. cit. p. 21.

35. Esposito R. Totalitarismo o biopolitica: per una interpretazione filosofica del Novecento. In: . Termini della politica: comunità, immunità, biopolitica. Milano: Mimesis; 2008. p. 159-81.

36. Esposito R. Op. cit. 2008. p. 176.

37. Esposito R. Op. cit. 2008. p. 179.

38. Agamben G. Profanations. Paris: Payot \& Rivages; 2005. p. 97.

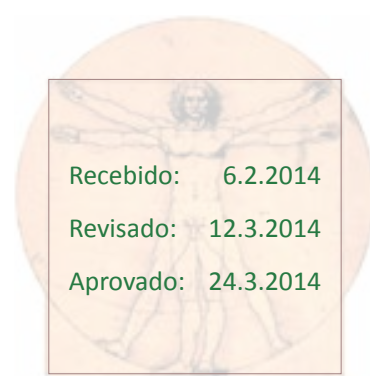

